\title{
On singularities of solution of the elasticity system in a bounded domain with angular corner points
}

\author{
Yasir Nadeem ${ }^{1}$ and Akhtar Ali ${ }^{2}$ \\ ${ }^{1}$ National Textile University, Faisalabad \\ ${ }^{2}$ Government College University Faisalabad
}

July 1, 2021

\begin{abstract}
This paper aims to give a mathematically rigorous description of the corner singularities of the weak solutions for the plane linearized elasticity system in a bounded planar domain with angular corner points on the boundary. The qualitative properties of the solution including its regularity depend crucially on these corner points or such types of boundary conditions. In particular, the resulting expansion of the solutions of the underlying problem involves singular vector functions, inlines, depending on a cer-

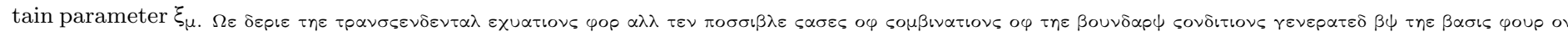

\section{Hosted file}

Manuscript file.pdf available at https://authorea.com/users/423057/articles/528628-onsingularities-of-solution-of-the-elasticity-system-in-a-bounded-domain-with-angularcorner-points
\end{abstract}

